\title{
Construction of MBD-Based Three-Dimensional Process Design Platform for Aircraft Manufacturing
}

\author{
Xudong $\mathrm{Xu}^{1, a}$, Song Chen ${ }^{2, b}$, Guangjun $\mathrm{Li}^{2, \mathrm{c}}$, Shuheng Wang ${ }^{3, \mathrm{~d}}$, Yizhang $\mathrm{Li}^{3, \mathrm{e}}$ \\ ${ }^{1}$ Department of Manager, Chengdu Aircraft Industrial (Group) Co.,Ltd, Chengdu, 610091, China \\ ${ }^{2}$ Department of Manufacture Engineering, Chengdu Aircraft Industrial (Group) Co.,Ltd, Chengdu, \\ 610091, China \\ ${ }^{3}$ Department of Process \& Tooling, Beijing Sysware Technology Co.,Ltd, Beijing, 100088, China

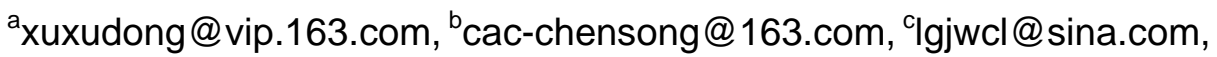 \\ dwangsh@sysware.com.cn, ${ }^{\mathrm{e}}$ liyz@sysware.com.cn
}

Keywords: MBD; Aircraft Manufacturing; Process Design; Management System

\begin{abstract}
Referring to the experience of aeronautical manufacturing enterprises abroad like Boeing and Dassault, it is necessary to build the three-dimensional design platform of aircraft manufacturing technology based on the model-based definition (MBD), integrate the existing engineering data of many systems including visualization process design, parts machining simulation, assembly process simulation, visual assembly, tooling design and so on, achieve the integration and sharing of information technology , the information management and evaluation of process design task, thereby it can increase the efficiency of the process design, shorten process preparation cycle.
\end{abstract}

\section{Introduction}

With the rapid development of computer technology, through the application of three-dimensional digital technology, foreign aeronautical manufacturing enterprises represented by Boeing and Dassault unify the aeronautical product digital design and manufacturing standards, integrate process design platform, ensure the consistency and standardization of basic data in the business applications system, increase the level of technological design effectively, shorten the development cycle of new aircraft greatly and reduce the development costs[1].

Through the long-term research of three-dimensional process design and simulation, CAPP system integration technology and so on, domestic aeronautical manufacturing enterprises break the key technology bottleneck of the model-based definition (MBD) [2], three-dimensional visualization design process[3], sheet metal forming simulation[4-6], the three-dimensional assembly process simulation [7], the three-dimensional tooling design[8] and so on. It sets up the corresponding data system, achieves a successful transformation from the traditional two-dimensional design and manufacturing process to three-dimensional digital design and manufacturing process in key technology areas, improves the quality of the process design greatly. Although the level of overall technological design of aeronautical manufacturing enterprises has made great progress, and applied and verified in all major and key projects fully, there is still a larger gap in the management of process task and engineering data.

Process knowledge and workflow have no effective management in process design phase.At present, a large number of engineering experience, process knowledge and workflow are basically mastered by a few experienced technical personnel, process design work is basically completed by them. These engineering experience, process knowledge haven't be combed to make it become explicit, reusable, executable and public information systems. Experienced project managers may be very well aware how the work content of the process design stage should be completed, and they can carry out the process design work rhythmically according to plan, but young project managers may not know how to carry out the project development work orderly, process work is often assessed and issued in the form of the meeting, they often struggle to cope with the various 
meetings, carry out the process design work passively, and they can't meet the needs of the project development.

Engineering data has no unified management in process design phase, and it is unable to achieve data sharing. The systems of three-dimensional visualization design process, sheet metal forming simulation, the three-dimensional assembly process simulation, the three-dimensional tooling design and so on are independent of each other, and they don't exchange information directly, The overall planning and program evaluation of process design still adopt the traditional management mode, mainly mannered through meetings, e-mails and reports, so three-dimensional digital design process does not maximize.

Therefore, referring to the experience of aeronautical manufacturing enterprises abroad like Boeing and Dassault, it is necessary to build the three-dimensional design platform of aircraft manufacturing technology based on the model-based definition (MBD), integrate the existing engineering data of many systems including visualization process design, parts machining simulation, assembly process simulation, visual assembly, tooling design and so on, achieve the integration and sharing of information technology, the information management and evaluation of process design task, thereby it can increase the efficiency of the process design, shorten process preparation cycle.

\section{The Goal of the Construction}

The three-dimensional design platform of aircraft manufacturing technology should make the mainstream programs of aircraft development process design explicit, public and standardization, it carries out the specific process standardization work, integrates the existing engineering data of three-dimensional visualization design process, process simulation and tooling design system, and integrates with PDM, ERP system. Specific objectives are as follows:

First, establish and develop the three-dimensional design platform of aircraft manufacturing technology with scalability, achieve all the technical work in the stage of aircraft development process design in the end.

Second, analysis process design work process and work nodes, form a standard template, included in the system database, realize the management and evaluation of the process design task.

Third, integrate the existing engineering data of three-dimensional visualization design process, three-dimensional assembly process simulation, three-dimensional tooling design system, integrate with PDM, ERP system and company Portal, achieve the unified management and sharing of engineering data.

\section{The Plan of the Construction}

Platform Framework. The three-dimensional design platform can achieve all the technical work in the stage of aircraft development process design. The basic function module includes business modeling, project task management, process management, engineering data management and maintenance management. The function module structure is shown in fig.1, and the data exchange framework is shown in fig.2.

Business Modeling.Business modeling should accord to the actual situation of project and business requirements, achieve the business modeling work, containing project modeling, task modeling, data modeling, modeling, form designer, report designer and other functions.

Task Management.Task management is mainly based on the progress stage of the project, completes the project task management, provides the function of task execution process, and it includes the list of project management, mission planning, execution monitoring, execution engine, problem management, statistical query and other functions. 


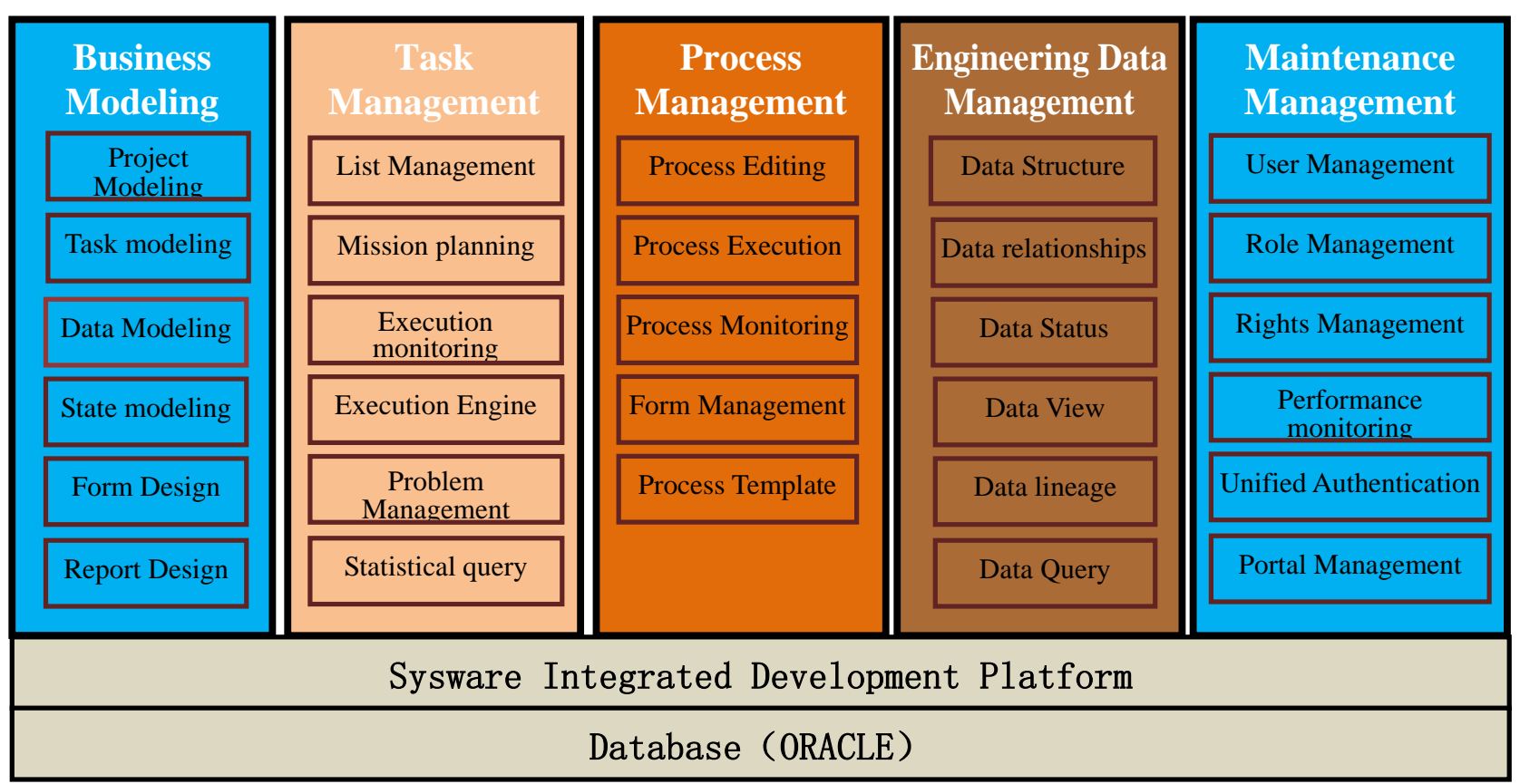

Fig.1. The function module structure of 3D process design platform

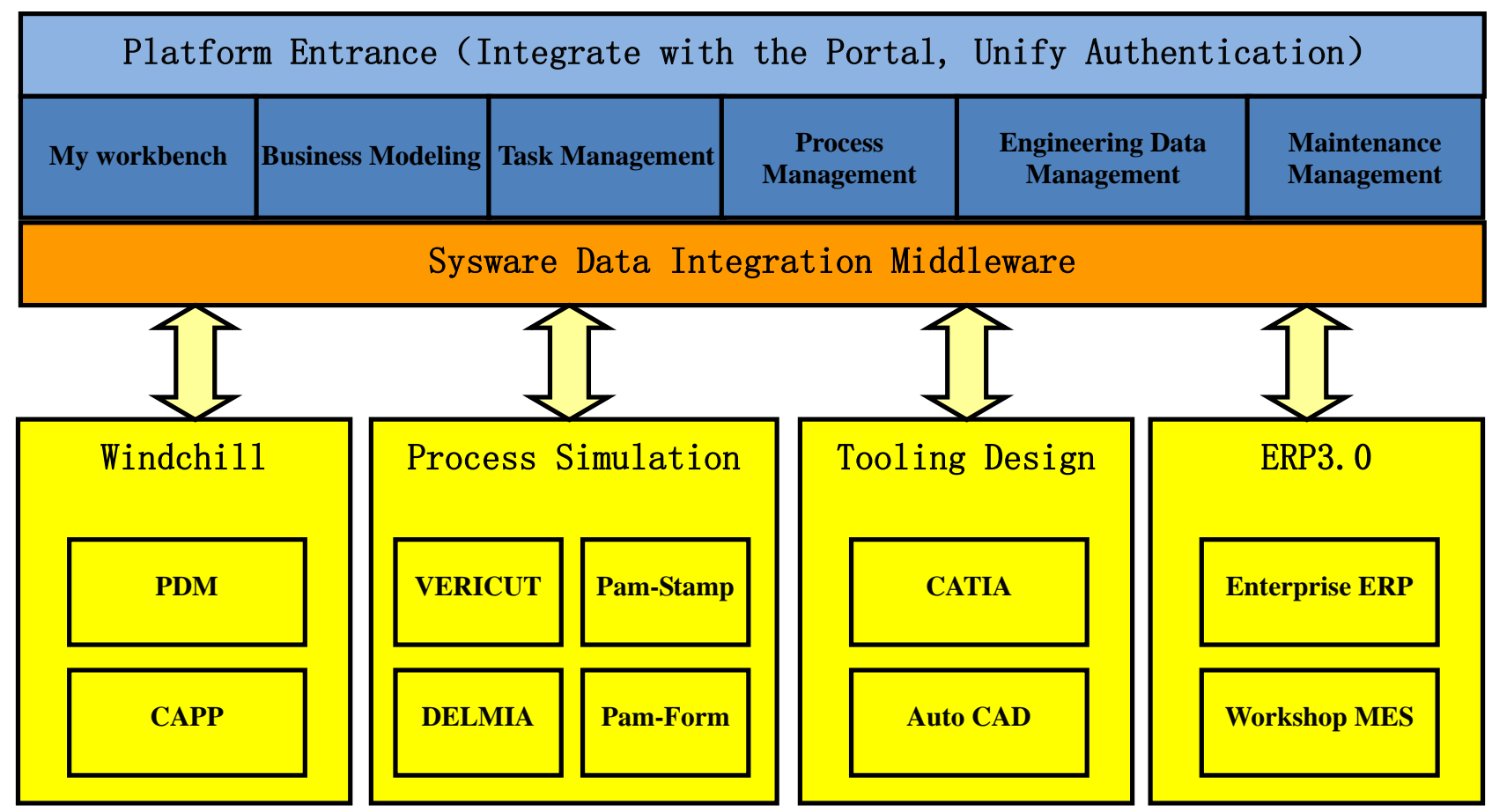

Fig.2. The data exchange framework of 3D process design platform

Process Management.The process management mainly combs the process workflow of aircraft developments, the strict technological processes establish the process data model. The model contains the corresponding sub-processes or sub-activities which contain the specific data of process tasks. The process management includes the process editing, process execution, process monitoring, form management, process template library and other functions, mainly complete comprehensive management of all the established processes of the system.

Engineering Data Management.Engineering data management achieves the unified management of all project data, supports to create the data in the data view of project engineering, and it obtains and checks all the data of tasks in the projects. Due to integrating the engineering data of three-dimensional visualization design process, three-dimensional assembly process simulation, three-dimensional tooling design system, you can view real-time the progress, raw data and video of 
the process simulation, tooling design, rather than the traditional sense reports.

Engineering Data Management module is able to maintain the data structure, and then form different views of the data, to satisfy the view demands of different people for data. It provides version management mechanism in the engineering data view and achieves the iteration data version management in the process of project implementation; it provides data spectrum function to record the evolution and relationships between data iterations, and then quickly analyzes data sources and impact analysis.

Maintenance Management.Maintenance management provides the management functions of organizational structure, users, roles, permissions and so on, and provides a unified authentication and the managements of single sign-on, traffic monitoring, storage, monitoring and so on. The system adopts the management method of separation of powers, with the minimum privilege separation and weights for the principle, the super-user privileges will be divided, and it can ensure the guarantee security and availability of the system.

\section{Conclusions}

Completing construction of MBD-based 3D process design platform for aircraft manufacturing will bring substantial benefits to aeronautical manufacturing enterprises:

First, unify process working environment and working platform, and unify process, process tasks, information query of the completed process task and so on.

Second, make the mainstream programs and sub-processes of aircraft development process design explicit, help project managers to know the specific phase of the current work processes, tasks and progress clearly.

Third, effectively build process tasks, work content, node requirements, realize the standardized distribution, processing and evaluation of the process task.

Finally, set up the integrated information processing system of process flow, process tasks, work progress, production site feedback, data query statistics and so on, realize to deal with the relevant information of process work in the unified interface.

\section{References}

[1] Hui W, Wang Y, Tao J, et al. Application of 3D Processing Technology in Aeronautical Manufacturing Industry. Aeronautical Manufacturing Technology [J].2013(13):43-46.

[2] Yu ZQ, Cheng S, Sun W, et al. Application of MBD-Based Three-Dimensional Module in Aircraft Manufacturing. Aeronautical Manufacturing Technology [J].2009(2):82-85.

[3] Qu HJ, Yu WJ. Research of Process Planning and Visualization Technology Based on 3D Model. Manufacture Information Engineering of China [J].2009(6):28-31.

[4] Li GJ, Yuan S, Xu XD, et al. Customizing Procedure of Finite Element Analysis for Sheet Metal Forming. Aeronautical Manufacturing Technology [J].2014(17):100-103.

[5] Zhang C, Sha L, Rui YL. Finite element analysis of aluminum-magnesium scandium alloy superplastic bulging process. Mechanical engineering materials [J].2008(2):81-84.

[6] Zhou Q, Du PA, Liu XB. Object-oriented finite element analysis technology and its implementation method research. Journal of System Simulation [J].2012(3):69-73.

[7] Jiang LP, Cheng WL, Huang DX. Virtual Simulation Method of Aircraft Assembly Procedure Based on Lightweight Model Technology. Aeronautical Manufacturing Technology [J].2013(12):26-29.

[8] Xi P, Li BL, Qu XD. Study on CAD Design Method of Aircraft Assembly Jigs. Aeronautical Manufacturing Technology [J].2002(08):55-57. 